Motrivivência $\quad$ Ano XX, No 31, P. 19-35 Dez./2008

\title{
O Jogo de Xadrez como Recurso Didático-Padagógico nas Aulas de Educação Física
}

Rosângela Ramos Veloso Silva'

\section{Resumo}

O presente estudo tem como objetivo desvelar as práticas pedagógicas no ensino-aprendizagem do jogo de xadrez em escolas públicas. Optou-se pelo uso de procedimentos metodológicos das pesquisas quantitativa e qualitativa através da utilização dos instrumentos: questionário, entrevista semiestruturada e observação participante.

A coleta de dados foi dividida em duas etapas, sendo, a primeira delas, o estudo exploratório em cinco escolas, na intenção de se obter critérios que levassem a um estudo aprofundado em apenas uma escola, através de um estudo de caso. Quanto ao ensino do xadrez em algumas escolas investigadas, as abordagens didáticas se confundem com uma

\begin{abstract}
This study aims to reveal the teaching practices in the teaching-learning of the game of chess in public schools. We chose to use the methodological procedures of qualitative and quantitative research through the use of instruments: questionnaire, semi-structured interview and participant observation. Data collection was divided into two stages, being the first one, the exploratory study in five schools, in order to obtain criterion that could lead to a detailed study in only one school, through a case study. Regarding the teaching of chess in some schools investigated, the didactic approach is confused with a "practice by practice", and the
\end{abstract}

1 Professora do Curso de Educação Física da Universidade Estadual de Montes Claros - Unimontes. Mestre em Educação- Universidade de Brasília- UnB. Contato: rosaveloso@yahoo.com.br. 
"prática pela prática", fundamentado apenas nos seus aspectos técnicos. Identificaram-se, também, no lócus do estudo de caso, ações pedagógicas baseadas em um processo dinâmico e ativo capaz de provocar mudanças, com o estabelecimento de estratégias cooperativas, dialógicas e interativas.

Palavras-chave: Jogo de xadrez; Recurso; Didático; Educação Física.

\section{Introdução}

O Jogo de xadrez é um instrumento pedagógico lúdico e potencializa o ensino-aprendizagem dialógico, empático e impulsionador das competências e habilidades de forma interativa, envolvente, autônoma, com participação qualitativa dos sujeitos da comunidade escolar. A prática pedagógica dos professores com o jogo de xadrez supostamente, pode deixar brechas no âmbito da sua intervenção levando-se em consideração o processo de formação no qual falta uma discussão pedagógica sobre o ensino desse jogo, impossibilitando a elaboração de uma prática metodológica para fundamentar o ensino do xadrez.

O xadrez é um dos jogos mais antigos da humanidade: atravessou quase 15 séculos e culturas diversas como a antiga Índia, Europa medieval, a União Soviética e o ocidente. Não se sabe exatamente teaching of chess based only on technical aspects. It was identified also in the locus of the case study, pedagogical actions of this game based on an active and dynamic process capable of causing changes in the establishment of cooperative strategies, dialogical and interactive.

Keywords: Game of chess; Resource didactic, Physical Education

quando e como surgiu o xadrez. "Sua história está tão intimamente relacionada com a civilização humana que estudá-la é entender melhor o próprio homem" (SHENK, 2007, p. 18).

Descobrir a origem do xadrez é complexo demais, pois existem mais de 40 lendas que relatam o surgimento desse magnífico jogo, no entanto, é no noroeste da Î́ndia que se encontram os indícios arqueológicos tidos como verdadeiros.

Em seu aspecto formal, o jogo de xadrez tem sido utilizado para estudar a memória, linguagem, lógica, inteligência; abarca igualmente a arte, devido ao impacto e valor estético, desafia a criatividade; também o esporte por envolver adversários, sob regras previamente definidas e mais atualmente vem despontando como uma ferramenta poderosa de aprendizado na educação superior e básica.

A prática do xadrez tem grande valor pedagógico. Por ser 
um jogo que reproduz uma situação de guerra, mas num contexto lúdico, no qual cada jogador tem de criar as suas estratégias, essa atividade proporciona muito mais que uma opção de lazer. Do ponto de vista pedagógico, é inegável que este jogo estimula capacidades do desenvolvimento cognitivo como raciocinar na busca dos meios adequados para alcançar um fim; organizar uma variedade de elementos para uma finalidade; imaginar concretamente situações futuras próximas; tomar decisões vinculadas à resolução de problemas.

A atividade enxadrística atrelada aos aspectos educacionais tem função peculiar no momento em que contrapomos os objetivos da educação escolar, organizada de forma intencional que tem como um dos principais pressupostos modificar e formar comportamentos nos alunos para que esses possam conviver harmonicamente em sociedade, nesse ponto traçamos um paralelo com as potencialidades do jogo de xadrez que favorece esse fim. Através do jogo, as crianças e jovens apresentam um desenvolvimento pessoal pela auto-descoberta e pela autonomia, vão se descobrindo, se respeitando, percebendo suas habilidades, potencialidades e seus limites.

O ensino do xadrez sempre encerrará em seu interior uma dimensão técnica. Mas uma dimensão técnica não significa nem tecnicismo nem performance. O lugar da performance não é na escola. O caráter lúdico pode prevalecer sempre numa aula de xadrez, desde que ela seja realmente uma aula, intencional, organizada, estruturada e planejada. Assim, os alunos tornam-se sujeitos autônomos e críticos a partir da premissa que as jogadas se efetuam por ações próprias, fazem suas escolhas e assumem seus erros como sinônimo de novo aprendizado.

Neste contexto, o xadrez como instrumento educativo transcende o jogo em si, impulsionando a construção de um processo de ensino dialógico, interativo, afetivo, criativo, comprometido, motivador, desafiador, e uma aprendizagem autônoma, subjetiva, libertária, cooperativa e solidária (GARCIA, 2008).

Apesar de se caracterizar como jogo individual, o desenvolvimento cooperativo torna-se presente pela necessidade de conviver harmonicamente com situações de liderar e ser liderado, do respeito e cordialidade presentes nas regras e no comportamento dos jogadores nos lances do xadrez. No jogo de xadrez há o rompimento de preconceitos e tabus pelo próprio sistema do jogo, no qual a reciprocidade entre os jogadores favorece seus aspectos lúdico e individual.

O trato com o jogo de xadrez em contexto educacional 
deve ser pautado em utilizá-lo como elemento motivador no estudo das disciplinas convencionais do currículo escolar, preparação técnica do jogo, para bem tratar os aspectos das regras e preparação didático-pedagógica, para a plena compreensão dos vínculos do jogo de xadrez com o meio escolar, principalmente na perspectiva educacional.

Assim como as potencialidades do xadrez são muitas, as alternativas para a implantação do ensino do xadrez na escola também são. Portanto, as estratégias metodológicas do ensino de xadrez nas escolas devem ser objeto de reflexão para bem integrá-lo ao currículo escolar, evidenciando sempre a real necessidade do enfoque multidimensional (xadrez como esporte, arte, ciência e responsabilidade social), e, nesse sentido, atendendo aspectos transdisciplinares, tão ofuscados em âmbito escolar, procurando evitar-se o reducionismo pedagógico no trato com o xadrez escolar.

Por ser uma atividade de reflexão intensiva e exigir uma tomada de decisão a cada lance da partida, é considerável o valor educacional do jogo de xadrez para promover a educação crítica e ativa da criança e do jovem, contribuindo para o desenvolvimento pessoal e cooperativo do seu praticante. $\mathrm{O}$ xadrez, como instrumento didáticopedagógico, deve ser orientado e conduzido. Com essa perspectiva, evidenciamos os aspectos do desenvolvimento pessoal e cooperativo através dos jogos, associando-os ao estudo e à prática sistemática do jogo de xadrez. Assim, tanto o desenvolvimento individual, quanto o desenvolvimento coletivo, podem ser proporcionados também pelo estudo e pela prática do jogo de xadrez, favorecendo os seus aspectos lúdicos e intelectuais.

Apesar de considerarem que o jogo de xadrez pode ser indicado pelos pressupostos de tomada de consciência, concentração e confirmadamente ativo nos processos cognitivos, o contexto escolar em suas atividades cotidianas é cerceado por amarras que dificultam a incorporação do jogo e suas diversas possibilidades, sendo considerado atividade extra, como recreação somente. A forma como a escola se organiza, com intensa preocupação no aproveitamento escolar, as persistentes "notas" fazem com que o jogo não encontre seu espaço.

\section{O Jogo de xadrez na educa- ção: alguns estudos}

A seguir, apresentaremos os principais trabalhos realizados considerando o xadrez e a educação, que não são muitos. Sá e 
Trindade (2005) investigaram experiências de ensino enxadrístico em meios escolar, periescolar e extraescolar. Comparando esse ensino enxadrístico nos quatro principais estabelecimentos investigados, constatou-se que ele apresentou mais problemas naquele onde o xadrez era disciplina obrigatória. Sendo assim, para explorar plenamente os recursos do xadrez escolar, este deverá ser de natureza optativa. A formação dos futuros professores de xadrez deverá levar em consideração os aspectos pedagógicos gerais, os aspectos específicos do conhecimento desse esporte, além de questões relacionadas a grupos de nível (e não grupos de idade, como a escola se propõe atualmente). Quanto ao xadrez, ele parece constituir-se como uma inovação pedagógica cuja potencialidade não foi completamente explorada.

Silva (2004) investigou os processos cognitivos no jogo de xadrez em escolares. Este estudo buscou analisar a tomada de consciência no jogo de xadrez em sujeitos "experts" de 8 a 17 anos, bem como analisar as jogadas erradas feitas pelos sujeitos. Os resultados parecem indicar que os processos cognitivos envolvidos no êxito e no fracasso numa partida de xadrez podem ser explicados pelo conceito de tomada de consciência.

Góes (2002) investigou o jogo de xadrez e a formação do professor de matemática, suas habilidades e competências necessárias à formação na visão do próprio licenciado em matemática, para serem comparadas com aquelas que podem ser desenvolvidas com a prática educativa do jogo de xadrez, além de ressaltar os benefícios da dimensão lúdica no processo ensino-aprendizagem. Nos resultados desse estudo, concluiu que os cursos de formação superior de professores de matemática, sobretudo em Salvador, precisam criar meios e condições que favoreçam o desenvolvimento de competências e habilidades em seus alunos, futuros educadores matemáticos, que irão atuar numa sociedade cada vez mais exigente, marcada pela dinâmica das relações sociais e do trabalho, onde o conhecimento matemático só tem sentido quando associado ao conjunto dessas competências. O jogo de xadrez, se utilizado adequadamente, poderá ser mais um agente desencadeador do desenvolvimento de algumas dessas habilidades e competências.

Araújo (2005), em seu estudo sobre o xadrez como instrumento pedagógico no processo ensino-aprendizagem, constatou que o xadrez é um precioso coadjuvante escolar, e até psicológico. Assim, pode-se utilizar inicialmente a motivação quase espontânea do aluno em relação ao xadrez visando 
a provocar ou facilitar a sua compreensão em outras disciplinas. Em uma segunda etapa, extrapola-se o universo artificial criado pelas regras do jogo como modelo de estudos de situações concretas. Isto pode aplicar-se a todos os campos do conhecimento - à história, à sociologia, ao direito e à literatura, entre outros, e, sobretudo, à matemática e à pedagogia.

Oliveira (2005) objetivou estudar as condutas de escolares no jogo de xadrez Simplificado, relacionando-as à coordenação das perspectivas espacial e social. Os resultados apontaram interdependência entre as condutas apresentadas no jogo, o desenvolvimento das perspectivas espacial e social em relações construtivas e integrativas. Os resultados revelaram ainda o jogo como uma possibilidade de observação de relações de operatoriedade crescente, o desenvolvimento das condutas do egocentrismo e indiferenciação da perspectiva, à reciprocidade mútua ou cooperação, tanto para a perspectiva espacial quanto social, em escolares.

Trindade Júnior (2006) realizou um estudo sobre a didática do ensino do xadrez nas escolas no município de João Pessoa e concluiu que, embora a forma de implantação do ensino do xadrez nessas escolas não seja unicamente como escolinha desportiva, pois algumas escolas têm o ensino do xadrez contemplado na sua matriz curricular, os dados coletados apontaram que, mesmo nesta condição de disciplina curricular, a abordagem didática se confunde com a de uma escolinha de prática desportiva, vendo-se o jogo de xadrez tão somente como um esporte, ou o jogo pelo jogo, tendo o ensino do xadrez fundamentado apenas nos seus aspectos cognitivos, sem acompanhamento pedagógico adequado, sem professores com formação ou preparação pedagógico-didática para o ensino do xadrez e sem uma estrutura física adequada para o desenvolvimento das múltiplas dimensões e potencialidades pedagógicas desse jogo.

\section{Metodologia}

Tendo como propósito desvelar as percepções dos professores de educação física sobre sua participação, execução e elaboração da prática pedagógica em relação às estratégias adotadas diante do jogo de xadrez, dentro de uma abordagem quantitativa e qualitativa. como instrumentos de pesquisas foram utilizados questionário, entrevista semiestruturada e observação participante.

Tendo em vista a dimensão do universo estudado, esta pesquisa utilizou-se, em um pri- 
meiro momento da investigação, um levantamento tipo survey que, no nosso entendimento, é o que nos possibilita alcançar o universo pretendido.

Segundo Babbie (2001), surveys são muito semelhantes a censos, mas deles se diferenciam porque examinam somente uma amostra da população enquanto o censo geralmente implica uma enumeração da população toda. Posteriormente, em um segundo momento, foi privilegiada a abordagem qualitativa como proposta de uma investigação mais aprofundada.

No primeiro momento da pesquisa foram aplicados questionários a 20 alunos do sexto ano do ensino fundamental de 5 escolas públicas da cidade de Montes Claros - MG, totalizando 100 alunos, escolhidos de forma aleatória. Os questionários foram analisados por intermédio do programa estatístico Statistical Package for the Social Science - SPSS (versão 13.5). As variáveis foram analisadas utilizando análise descritiva estatística percentual. Os dados foram distribuídos em porcentagem e frequência para melhor análise que nos mostrou qual das escolas investigadas possui a implantação do jogo de xadrez de forma mais inovadora, organizada e emancipada.

No segundo momento da pesquisa foi realizada observação de aulas e entrevista semiestruturada com um professor de educação física. A interpretação se realizou por análise de conteúdos e análises dos registros de observação, que se realizou cotidianamente sob formato do diário reflexivo. Segundo Alves-Mazzotti e Gewandsznajder (1999), no diário reflexivo, o pesquisador anota suas intuições, dúvidas, sentimentos, percepções, relacionadas à investigação, bem como as razões metodológicas feitas durante o processo.

\section{Análise e discussão de dados}

Na perspectiva de conhecer as concepções de educação que predominam nas práticas pedagógicas dos professores que ensinam xadrez; identificar as abordagens didáticas do ensino do xadrez e estabelecer relações entre as práticas pedagógicas do ensino do xadrez com a formação docente foram reveladas nesta pesquisa. Respondendo nossas questões, várias informações foram obtidas em diferentes comunidades escolares que possuíam o jogo de xadrez como fenômeno educativo. Para compreender o fenômeno jogo de xadrez dentro de uma perspectiva educacional, o caminho percorrido foi coerente e significativo de acordo com os objetos de estudo aqui mencionados. 
Na busca pela amostra, foram escolhidas cinco escolas públicas da cidade de Montes Claros (MG), com a intencionalidade de estas apresentarem diferentes características quanto ao seu público, além da intenção de conhecer a realidade do ensino do jogo de xadrez nos vários extremos dessa cidade, já que as escolas situam-se nas regiões norte, sul, leste, oeste e central, o que foi suficiente para suprir as necessidades do estudo. Assim, foram abordados em ambientes escolares de prática do jogo de xadrez os indivíduos que constituiriam a população da referida pesquisa.

Um questionário com 30 questões abertas e fechadas foi aplicado a 20 alunos dos sextos anos do ensino fundamental de cada uma dessas escolas. Desta forma, obtivemos informações dos seus conhecimentos sobre as práticas pedagógicas do jogo de xadrez, bem como os aspectos didático-pedagógicos implicados no jogo. Como foco do estudo, a pesquisa limitou-se em três competências básicas referentes à visão dos alunos sobre: participação, conhecimentos e estratégias da prática pedagógica dos professores diante do ensino do jogo de xadrez.

Os resultados encontrados, nesse primeiro momento da pesquisa, nos levam a acreditar que o ensino do jogo de xadrez nas escolas necessita da atuação de pro- fissionais da educação com intensa capacidade de instrumentalização dos fundamentos da educação para garantir o xadrez como instrumento pedagógico capaz de envolver o corpo discente de forma satisfatória.

O conhecimento do jogo de xadrez é constituído na interação do sujeito-objeto, via mediação a princípio do professor, sendo sua função principal a de orientar a construção do conhecimento auxiliando para que o aprender tenha sentido, valorizando as pequenas descobertas e as novas dúvidas e, sobretudo, formulando novas questões e promovendo reflexões. De acordo com as análises dos questionários, a maioria dos professores de educação física ao propor ensinar e desenvolver o jogo de xadrez não percebem em suas ações pedagógicas as individualidades dos sujeitos cognitivos, sociais e afetivos diferenciados, autores de seus pensamentos e ações, questões que favoreçam o envolvimento e desenvolvimento dos alunos em situação lúdica do jogo, fatores esses que não foram identificados na visão de grande parte dos alunos ao apontarem em muitas questões o pouco envolvimento, o descaso e a falta de conhecimentos das possibilidades do jogo de xadrez, o que nos possibilita afirmar que as práticas pedagógicas diante do jogo de xadrez adotadas nessas escolas 
são práticas descontextualizadas, sem fundamentação, "prática pela prática" com uma devida ausência de fatores essenciais na formação do sujeito cognoscível e integral, prevalecendo aspectos técnicos do jogo dentro de uma concepção de educação tradicional.

Contrapondo a ausência de unidade encontrada na maioria das escolas, evidenciamos em uma das escolas conhecimento sistematizado e coerente na visão dos alunos quando indagados sobre o ensino do jogo de xadrez naquela escola. Possuindo um sistema de ensino-aprendizagem do jogo de xadrez de forma bastante envolvente e comprometida com o processo de ensino-aprendizagem respaldado pela formação humana, sendo por nós apontada como modelo de desenvolvimento do jogo de forma sistemática, organizada e intencional. Portanto, essa escola passou a fazer parte de uma investigação mais aprofundada, priorizando a aproximação da pesquisadora com o ambiente pesquisado na utilização de suas percepções em prol do estudo. Foram eleitas categorias para análise dos resultados do estudo de caso:

\section{As intenções implícitas nas práticas pedagógicas}

As intenções implícitas nas práticas pedagógicas da professora foram facilmente perceptíveis no momento em que ela deixa claro seu compromisso político, técnico e pedagógico com o ato de ensinar, ao informar como iniciou a prática do xadrez na escola:

Em uma reunião o diretor $\mathrm{CO}-$ locou para todos os professores que tinha recebido alguns tabuleiros e que pretendia colocar no pátio em mesas de alvenaria, deixando livre, aí eu pedi pra ele mostrar, aí eu disse: nossa mas esse material é de primeira! Não seria possível deixá-lo num local específico, coloquei pra ele assim: você me permitiria ensinar meus alunos e incluir o xadrez no meu planejamento anual?

Essa prática educativa do professor no ambiente escolar é algo que transcende a simples participação e transmissão de conhecimentos, ele é sujeito de seu próprio trabalho e ator de sua pedagogia, pois é ele quem a modela, quem lhe dá corpo e sentido no contato com os alunos. A educação é algo além da simples iniciativa profissional em dominar os conteúdos e apresentar capacidade pedagógica para auxiliar na compreensão dos alunos. Neste sentido, o professor é aquele que faz a mediação das relações educativas e, desta forma, pode transformar a realidade escolar e social (TARDIF, 
2007). Colocar os tabuleiros de xadrez em locais de fácil acesso, deixando livres para que os próprios alunos estabelecessem uma relação de aprendizagem com o jogo não é, em medida alguma, uma atitude viável diante do processo de formação humana que se caracteriza, em tese, por uma intervenção comprometida. Nesse aspecto, foi louvável a atitude de ação da professora ao intervir propondo que o ensino fosse direcionado.

Nesta perspectiva, Freire (2005, p. 25, grifo nosso) destaca que "[...] ensinar não é transferir conhecimento, mas criar as possibilidades para a sua produção ou a sua construção, e nas condições de verdadeira aprendizagem os educandos vão se transformando em reais sujeitos da construção e da reconstrução do saber ensinado."

Ao ser indagada sobre o porquê do ensino do xadrez na escola em que trabalha, obtivemos a seguinte resposta:

Porque como foi um aprendizado que tive, no meu tempo de faculdade, eu sempre quis. Sempre por onde passei que tinha, havia ou os diretores se propunham a providenciar eu sempre trabalhei o xadrez, (Sempre trabalhou?) Sempre trabalhei. Mas esse é o segundo local onde eu encontro uma es- trutura... (Perfeita?) Exato! Agora aqui foi a melhor estrutura... além de tabuleiros, tem uma sala própria.

Com base nos estudos de Cunha (2005), os saberes que podem ser observados no professor é o resultado da apropriação que ele faz da prática e dos saberes histórico-sociais. A apropriação é uma ação recíproca entre os sujeitos e os diversos âmbitos ou integrações sociais. Só que elas são diferentes nos sujeitos, eles se apropriam de diferentes coisas em função de seus interesses, valores e crenças. Isto é demonstrado pelo diferenciamento existente entre o comportamento dos professores que seguem propostas pedagógicas distintas, refletindo e antecipando sua história.

Para tanto, o conhecimento acadêmico que a professora adquiriu durante seu processo de formação foi revelado como aprendizado significativo, tomado como necessário capaz de ser apresentado em suas ações pedagógicas.

Corroborando com essa perspectiva, Tardif (2007) nos diz que os saberes são plurais, formados pelos saberes da formação profissional, saberes disciplinares, saberes curriculares e saberes experienciais. Para ele, o professor é "[...] alguém que deve conhecer sua matéria, sua disciplina e seu programa, além de 
possuir certos conhecimentos relativos às ciências da educação e à pedagogia e desenvolver um saber prático baseado em sua experiência cotidiana com os alunos" (TARDIF, 2007, p. 39).

\section{Concepções de educação}

De acordo com os dados levantados, inferimos uma concepção de educação dialética, evidenciando-se professora e alunos apropriando-se de uma prática social vivenciada por eles em suas realidades, articulando conteúdos com saberes e vivências culturais na apropriação do conhecimento.

Foi viável considerar a inserção da professora como ser histórico dentro de um contexto sociocultural atuante com uma postura crítica, reflexiva, criativa, inovadora, e ainda de forma tímida, interdisciplinar, com isso, contribuindo efetivamente com uma prática pedagógica comprometida. Corroborando com estas evidências, destacamos algumas falas da professora:

Eu considero o xadrez um conteúdo muito importante, desde que, a partir do momento, que ele trabalha o ser humano de forma toda, né, então ele propicia a melhora de memorização da pessoa, a solidariedade, ele trabalha princípios morais, sabe... a formação de caráter, eu vejo tudo isso no jogo de xadrez, eu consigo enxergar tudo isso no xadrez.

Considera-se, assim, que o docente, em sua trajetória, constrói e reconstrói seus conhecimentos conforme a necessidade de utilização destes, sua experiência, seus percursos formativos e profissionais, dessa forma é importante considerar o processo de formação e vivência pessoal de cada professor refletido em suas ações pedagógicas.

[...] porque é um jogo de honestidade né?. Por que você fala que é um jogo de honestidade? Por que ele não aceita golpe baixo, nem blefe, você tem que ser franco.. apesar dele ser em alguns momentos violentos... por que é uma batalha, não é mesmo? É, nele trava-se uma uma batalha... mas em momento algum você é desleal um com outro, tem que ser cara a cara, frente a frente.

As falas da professora vêm respaldar a nossa forma de classificá-la como atuante dentro de uma concepção de educação dialética.

E nas aulas você faz essa mediação com os alunos?

Faço, faço... Relaciono sim porque eu aprendi assim, e coloco para eles esses valores... Valo- 
res de caráter... que é cobrado na vida e no xadrez e também... quando a gente aprende realmente, nós percebemos e parece que volta pra si, você vivencia tão bem o xadrez... que dá impressão que você é o rei.

Esse relato parece estar relacionado à ideia que muito do que fazemos reflete nosso relacionamento, mantido em algum lugar dentro de nós, com aqueles que nos ensinaram. Algumas vezes, há quase o estranho sentimento de sustentar suas relações internas com seus próprios professores e ídolos. A influência dos professores em nossas vidas também foi enfatizada por Freud (1970, p. 282) quando escreveu: "É difícil dizer se o que exerceu mais influência sobre nós e teve importância maior foi a nossa preocupação pelas ciências que nos eram ensinadas, ou a personalidade de nossos mestres".

Nesse sentido, Freire (2006) corrobora que,

Transformar a experiência educativa em puro treinamento técnico é amesquinhar o que há de fundamentalmente humano no exercício educativo: o seu caráter formador. Se se respeita a natureza do ser humano o ensino dos conteúdos não pode dar-se alheio à formação moral do educando. Educar é substantivamente formar (p. 33).
Conforme o jogo é apresentado pela professora como fator de concentração e silêncio e, nesse sentido, apontado como caráter de seriedade presente, faz-se necessário contrapor tais características com os conceitos de jogo e, para isso, nos apoiamos mais uma vez em Huizinga (2007), que aponta o jogo à primeira vista oposto à seriedade, sendo uma afirmação imediatamente refutada pelo mesmo autor ao afirmar: "[...] caso pretendamos passar de o jogo é não-seriedade para o jogo não é sério, imediatamente o contraste torna-se-á impossível, pois certas formas de jogo podem ser extraordinariamente sérias" (2007, p. 8).

\section{Abordagens didáticas}

Ao ser abordada para falar sobre quais benefícios o xadrez traz para seus alunos, mais uma vez, a professora foi contundente e precisa referenciando as ações do jogo com situações da vida diária:

Nossa!!! Como tem!...concentração, importantíssimo para nossos alunos..., tão importante nos dias de hoje, nessa vida de hoje... tão corrido, que nós não conseguimos parar para refletir e observar o meio, né? Então... Tudo que acontece em nosso redor, então... o xadrez nos proporciona 
isso, desenvolver esse tipo de capacidade de observar por vários ângulos, né?... é às vezes você só foca de uma forma na sua vida, como sair de um problema e tem variáveis... que o jogo te propõe isso... te proporciona isso... desde que você tenha calma, paciência... cautela.

Percebemos nas falas da professora a nítida referência do xadrez com a vida cotidiana, no tabuleiro simulamos lutas que servem de preparação para as provas mais importantes, que são as da vida. $\mathrm{O}$ esporte fornece uma oportunidade ímpar nesse sentido, ao ofertar um simbolismo de situações adequadas para as lutas diárias. No xadrez, ao ser derrotado após uma intensa batalha intelectual, olhamos para o adversário e apertarmos sua mão como gesto de reconhecimento pela sua atuação. Lidar com o ganhar e perder é tema constante na vida de quem joga xadrez. Isto o prepara para os sucessos e insucessos dos desafios maiores, que enfrentamos em nossas vidas. As derrotas e vitórias na vida devem ser vistas como um processo de evolução natural que deve ser encarado com tranquilidade e sabedoria, sendo assim o xadrez é útil como objeto de simulação de fatos da vida cotidiana, onde ganhar e perder, tomada de decisão, criatividade, estar sempre atento para soluções de problemas cada vez mais urgentes e complicados, fazem parte do jogo e da vida.

\section{Relações entre prática peda- gógica e formação docente}

Foi perguntado sobre qual a preparação da professora para o ensino do xadrez:

Eu tive uma preparação acadêmica... eu aprendi na faculdade... você teve a disciplina? Eu tive a disciplina de esportes complementares que tinha o jogo de xadrez. E depois disso? Depois da faculdade eu fiz algumas oficinas e cursos.

O jogo de xadrez nas escolas não deve ser ensinado como fim em si mesmo. Não é apenas um jogo a ser ensinado como passatempo ou um desporto para a disputa de prêmios em torneios escolares, mas sim um meio didático-pedagógico com múltiplas utilidades, um elemento motivador da aprendizagem interdisciplinar. Saber utilizar essa potencialidade requer sensibilidade, criatividade e, principalmente, preparação didático-pedagógica, visando resultados positivos. Nesse aspecto, a formação básica e continuada da professora certamente favorece todo seu envolvimento na condução de sua práxis. 
Nesse sentido, Veloso e Sá (2009) apontam que, apesar de ser apresentado em várias áreas do conhecimento humano, o jogo, pouco compreendido, é reduzido a um simples objeto de estudo, desconsiderado pelas várias possibilidades que sua prática pode oferecer.

Assim, concretizar a corporalidade como eixo organizador e norteador único da educação física escolar é reconhecer que o atual modelo escolar não dá conta de tratar a proposta maior de formação humana em toda sua plenitude. Resumir a seu objeto de ação apenas a sua dimensão motriz talvez seja a maior das dificuldades de legitimação da educação física no espaço escolar.

A educação física, como parte do processo educativo, reconhecida como disciplina pedagógica que compõe a grade curricular da educação formal, contempla princípios e fins da educação. Assim, cabe ao professor de educação física buscar novas experiências e participar da construção de suas ações e práticas, para que este seja o vetor da produção de cultura, e não apenas de sua reprodução (BARTHOLO, 2000).

\section{Considerações finais}

Quanto ao ensino do xadrez em algumas escolas investi- gadas, as abordagens didáticas se confundem com uma "prática pela prática", vendo-se o jogo de xadrez tão somente como um jogo pelo jogo, tendo o ensino do xadrez fundamentado apenas nos seus aspectos técnicos, sem acompanhamento pedagógico adequado, sem professores comprometidos e envolvidos com o ensinar, com estrutura física pouca adequada para o desenvolvimento das múltiplas dimensões e potencialidades pedagógicas do jogo de xadrez. Este estudo também levanta muitos argumentos e indícios da utilidade do jogo de xadrez como subsídio pedagógico a ser inserido em meio escolar, visando uma educação em valores humanos, por meio da vivência, reflexão e práxis inovadora desenvolvida. A pesquisa teve por assertiva que, através de uma atuação didática pedagógica comprometida, podemos levar às escolas novos conceitos de relações humanas, resgatando valores por meio do jogo de xadrez que oportunizem o aprimoramento de aspectos cognitivos, afetivos e sociais, princípios importantes na busca de uma educação de qualidade.

Com intuito de transpor ao jogo de xadrez as concepções condicionantes do ato educativo, conseguimos vislumbrar essa transferência em muitos momentos da ação pedagógica inovadora e, principalmente, comprometida. A 
educação implica contribuir para a constituição de um sujeito social e cultural que possa viver e conviver bem em sociedade, dela participando de forma ativa e produtiva, imbuído de valores de cidadania. As práticas pedagógicas do jogo de xadrez baseadas em um processo discursivo e dialógico são capazes de provocar mudanças quando compreendido como processo dinâmico, ativo e singular quando o sujeito internaliza seus preceitos, os transforma e intervém no universo que o cerca. Diante disso, enfatizamos que as ações pedagógicas diante do jogo de xadrez necessitam ser encaradas como um importante momento de aquisição de conhecimentos e, como tal, a sua existência precisa ser valorizada pela comunidade escolar, pela estrutura curricular e pelos profissionais da educação.

Julgamos que as reflexões que apresentamos neste estudo ressaltam a importância de esse jogo, quando inserido no contexto educacional, ser percebido por uma complexidade da prática pedagógica dos elementos que o permeiam. Somente assim, será capaz de contribuir com a formação dos alunos em sua integralidade.

Não seremos conclusivos, pois esta pesquisa abre novas possibilidades, considerando que ainda há muito o que ser desvelado, no sentido de possibilitar a integração do ensino do xadrez na estrutura pedagógica da escola, levando a uma necessária reflexão sobre as suas formas de implantação, principalmente a proposta de lançar um olhar crítico sobre a abordagem didática do ensino do xadrez em outras escolas, descrevendo-as e posteriormente tentando estabelecer relações entre alguns aspectos que a compõem, tais como o perfil docente, concepção pedagógica da escola em relação ao xadrez, visando, com isso, à implantação de ensino do jogo em âmbito escolar e não apenas como atividade extracurricular, porém contemplado na cultura escolar de forma integrada.

\section{Referências}

ALVES-MAZZOTTI, Alda Judith; GEWANDSZNAJDER, Fernando. $\mathbf{O}$ método nas ciências naturais e sociais: pesquisa quantitativa e qualitativa. 2. ed. São Paulo: Pioneira, 1999.

ARAÚJO, André de Almeida. O xadrez como atividade lúdica na escola: uma possibilidade de utilização do jogo como instrumento pedagógico no processo ensino-aprendizagem. 2005. Disponível em: < http:// www.faculdadesocial.edu. br/semanaacademica2006/ 
TEXTOS/ANDRE \% 20DE \% 20 ALMEIDA \% 20ARAUJO.pdf > . Acesso em 01 jul. 2009.

BABBIE, Earl. Métodos de pesquisas de survey. Belo Horizonte: Editora UFMG, 2001.

BARTHOLO, Márcia Fernandes. A Construção do conhecimento e o Projeto Político Pedagógico da Educação Física. Revista Pensar a Prática, Rio de Janeiro, v. 3, p. 53-64, jun. 2000.

BROUGĖRE, Gilles. Brinquedo e cultura. 3. ed. São Paulo: Cortez, 2000.

CUNHA, Maria Izabel da. O bom professor e sua prática. Campinas: Papirus, 2005.

FREIRE, João Batista (Org.). O jogo dentro e fora da escola. Campinas: Autores Associados, 2005.

FREIRE, Paulo. Pedagogia da autonomia. 34. ed. São Paulo: Paz e Terra, 2006.

FREUD, Sigmund. As perspectivas futuras da terapêtica psicanalítica. Rio de Janeiro: Imago, 1970.

GARCIA, Melquisedek Aguiar. A transcendência interdisciplinar do xadrez na construção do processo de ensino/aprendizagem no campo e na cidade. 2008. 111f. Monografia (Trabalho Final de Curso) - Universidade de Brasília, UnB, Brasília, DF.

GOES, Daniel de Cerqueira. O jogo de xadrez e a formação do professor de matemática. 2002. 106f. Dissertação (Mestrado)

- Programa de Mestrado em Engenharia de Produção. Universidade Federal de Santa Catarina, Santa Catarina, 2002. HUIZINGA, Johan. Homo ludens: o jogo como elemento da cultura. São Paulo: Perspectiva, 2007.

OLIVEIRA, Francismara Neves de.

Um estudo das interdependências cognitivas e sociais em escolares de diferentes idades por meio do jogo xadrez simplificado. Campinas, SP: [s.n.], 2005.

SÁ, Antônio Villar Marques;

TRINDADE, Walmeran JÚNIOR.

$O$ xadrez como instrumento pedagógico: manifesto pela sua inclusão curricular nos cursos de pedagogia e de licenciatura. In: Colóquio Internacional de Políticas e Práticas Curriculares, II., 2005, João Pessoa, 2005.

SILVA, Wilson da. Processos cognitivos no jogo de xadrez. 2004. 196f. Dissertação (Mestrado em Educação) Universidade Federal do Paraná, Paraná, 2004.

SUNYÉ, Jaime. Xadrez escolar: um instrumento multidisciplinar numa escola de qualidade. 2006. Disponível em: < http://www. fexerj.com.br/texto_sunye.htm $>$. Acesso em: 29 ago. 2008.

TARDIF, Maurice. Saberes docentes e formação profissional. 2. ed. Petrópolis: Vozes, 2007. 
TRINDADE JÚNIOR, Walmeran José. A didática do ensino do xadrez nas escolas no município de João Pessoa - PB. 2006. Monografia (Aperfeiçoamento/ Especialização em Educação). Centro Universitário de João Pessoa, João Pessoa, 2006.

VELOSO, Rosângela Ramos; SÁ, Antônio Villar Marques. Reflexões sobre o jogo: conceitos, definições e possibilidades. Revista Efdeportes, Buenos Aires, ano 14, n. 132, maio 2009. Disponível em: < http:// www.efdeportes.com/efd132/ reflexoes-sobre-o-jogo.htm $>$. Acesso em: 28 maio 2009.

Recebido: 15/fevereiro/2010. Aprovado: 20/abril/2010. 